\title{
The Links between Accounting and Tax Reporting: The Case of Bad Debt Expense in the Italian Context
}

\author{
Simone Poli ${ }^{1}$ \\ ${ }^{1}$ Department of Management, Università Politecnica delle Marche, Ancona, Italy \\ Correspondence: Simone Poli, Department of Management, Università Politecnica delle Marche, Piazzale R. \\ Martelli 8, 60121, Ancona, Italy. Tel: 39-071-220-7258. E-mail: s.poli@univpm.it
}

Received: February 26, 2015

Accepted: March 19, $2015 \quad$ Online Published: April 25, 2015

doi:10.5539/ibr.v8n5p93

URL: http://dx.doi.org/10.5539/ibr.v8n5p93

\begin{abstract}
This study shows the way tax rules, rather than accounting ones, affect the measurement of receivables for the purpose of preparing the financial statements of Italian private (unlisted) companies according to national accounting standards. Through the distribution approach, it shows that Italian companies are likely to account for bad debt expense that corresponds to the maximum tax-deductible amount. Considering that the impact of tax rules on the preparation of the financial statements may affect the quality of earnings, the main implication of the findings of this study is that the earnings reported by Italian companies are not unconditionally informative regarding the company's performance. In other words, they may be of poor quality. As a result, they should be interpreted with caution by those who use financial statement information.
\end{abstract}

Keywords: accounting, taxation, bad debt expense, private companies, Italy

\section{Introduction}

Our study explores the relationship between accounting and tax rules for the preparation of financial statements. Previous studies (e.g., Hogendoorn, 1996; Lamb, Nobes, \& Roberts, 1998; Nobes, 1998, 2008; Aisbitt, 2002; Nobes \& Schwencke, 2006; Oliveras \& Puig, 2007; Gee, Haller, \& Nobes, 2010; Istrate, 2011; Gavana, Guggiola, \& Marenzi, 2013) have shown that this relationship changes from country to country and within the same country, over time.

Some of these studies have focused on whether and how the tax rules affect accounting measurements (e.g. Nobes \& Parker, 2008). Our study adds to this literature by delving into the area of the measurement of receivables for the purpose of preparing the financial statements of Italian private (unlisted) companies according to national accounting standards. The measurement of receivables is an issue of great interest for those who are interested in financial statement information. In fact, receivables are generally a relevant item on financial statements, on the one hand, and the measurement of receivables can have a relevant impact on the results of companies (because of the bad debt expense that may arise), on the other hand.

The case we investigate appears to be emblematic of the relationship between the Italian system of accounting and the tax rules for the preparation of financial statements. In fact, the Italian accounting rules regarding the measurement of receivables do not prescribe any behaviors that are immediately applicable, but provide only general guidelines (e.g., Marasca, 1999; Quagli, 2013). Instead, the Italian tax rules regarding the measurement of receivables prescribe behaviors that are immediately applicable, providing specific guidelines to determine the amount of tax-deductible bad debt expense.

Through the distribution approach, that is based on the graphical and statistical analysis of the frequency distribution of bad debt expense recorded in financial statements, our study aims to show whether and how the tax rules impact on the measurement of receivables for the purpose of preparing financial statements. In doing so, our study enriches the knowledge on the relationship between accounting and tax rules for the preparation of financial statements in the Italian context, enriching the findings of the Gavana et al. (2013) study that has analysed such an issue in more general terms, mainly theoretically.

The relationship between accounting and tax rules for the preparation of financial statements and, in particular, the fact that the tax rules can affect accounting measurement, may have important implications for the quality of earnings. In fact, Dechow, Ge, and Schrand (2010, p. 385) have found that "[t]ax regulations are a [...] 
commonly studied determinant of earnings quality, [...] because the regulations affect accounting choices". Thus, our study also enriches the knowledge on the quality of the earnings of Italian companies.

Our study proceeds as follows. Section 2 illustrates the Italian accounting and tax rules concerning the measurement of receivables and develops the research hypothesis. Section 3 describes the research design and the sample selection. Section 4 shows and discusses the empirical results. Section 5 summarises the findings and highlights the main contributions of our study as well as its limitations and possible further research opportunities.

\section{The Measurement of Receivables in the Italian Context: An Overview of the Italian Accounting and Tax Regulations and the Development of the Research Hypothesis}

According to the Italian accounting standard no. 15, receivables must be measured at the (estimated) net realizable value, that is, the best estimate for the amount of cash a company expects to collect from its receivables. It corresponds to the face value of receivables less the balance in the allowance for doubtful accounts. The amount of the allowance for doubtful accounts should be sufficient (adequate, but not excessive) to cover, according to the matching principle, both those existing situations of unrecoverable accounts as well as those that have either not yet manifested themselves or are feared or latent. The amount to be credited to the doubtful accounts allowance should be determined by using an "analytical" procedure. It consists in the analysis of each account receivable, taking into account any relevant information for estimating the portion of the account receivable that could not be collected. Nevertheless, in certain situations (for example, when credits are highly fragmented), instead of the procedure described above, bad debt expense can be estimated by using "synthetic" procedures that involve applying certain formulas, such as the so-called "percentage of sales (or accounts receivable) method". However, these formulas cannot be transformed into a rule. They are only practical tools, the validity of which must be constantly monitored. Therefore, they must be changed whenever the conditions on which the formulas are based change. These formulas are acceptable only if they allow the company to achieve results that are substantially similar to those that would be achieved by using the "analytical" procedure described above.

According to the Italian tax rules (in particular, article no. 106 of the Law of 22nd December 1986 no. 917):

- The maximum tax-deductible amount of bad debt expense in a fiscal year is $0.50 \%$ of the face value or the acquisition value of the accounts receivables reported in the balance sheet at the end of the fiscal year;

- The basis of calculation of the tax-deductible amount of bad debt expense consists of the face value or the acquisition value of the trade receivables, that is, those receivables that arise from selling merchandise or providing services to customers on credit, that are not covered by credit risk insurance; thus, the basis of calculation excludes: all non-trade receivables, that are receivables other than accounts receivables (some examples of non-trade receivables include interest receivables, income tax receivables, insurance claims receivables and receivables from employees, loans provided to other entities), the trade receivables that are covered by credit risk insurance, within the limit of the coverage; some kinds of trade receivables sold to third parties (e.g. Factoring operations);

- The tax deductibility of bad debt expense is no longer allowed when the balance of the allowance for doubtful accounts has reached $5.00 \%$ of the face value or the acquisition value of the tax-relevant receivables (i.e., those that are included in the basis of calculation referred to above) resulting in the balance sheet at the end of the fiscal year.

The Italian accounting rules provide only general guidelines. They set out the general principles that those who prepare the financial statements should follow for the measurement of receivables. They, however, do not give clear guidance that is directly applicable. The Italian tax rules, instead, give specific guidelines. They set out both the percentage of bad debt expense that is deductible in a fiscal year and the basis of calculation on which to apply such a percentage. Thereby, they give clear guidance that is directly applicable.

As mentioned earlier, the links between accounting and tax regulations have already been explored in literature (e.g., Lamb et al., 1998; Nobes \& Schwencke, 2006). Nobes and Schwencke (2006), in particular, have proposed the classification shown in Table 1.

Considering the Italian accounting and tax rules related to bad debt expense we have summarized above, we believe that the link between them can fall under "Case IV" of the classification proposed by Nobes and Schwencke (2006). As a result, we expect that the tax rules are followed for tax purposes and also for financial reporting purposes. We expect this for two reasons; first, because the accounting rules are not sufficiently specific (or singular) and second, because Italian companies may tend to maximize the tax benefit arising from 
bad debts. Therefore, in cases where the risk of default is low, Italian companies would increase the amount of bad debt expense, claiming or reporting the maximum tax-deductible amount; in cases where the risk of default is high, Italian companies would decrease the amount of bad debt expense, keeping the claim within the tax-deductible limit (Gavana et al., 2013).

The above considerations suggest the following research hypothesis:

$\mathrm{H}_{0}$ : Italian companies are likely to account for amounts of bad debt expense that correspond to the maximum tax-deductible amount.

Table 1. Classification of the links between accounting and tax regulations

\begin{tabular}{|c|c|c|}
\hline Cases of links & Labels of links & Description \\
\hline Case I & Disconnection & $\begin{array}{l}\text { The different tax and financial reporting rules (or different options) are followed for their } \\
\text { different purposes. }\end{array}$ \\
\hline Case II & Identity & Identity between specific (or singular) tax and financial reporting rules. \\
\hline \multirow[t]{2}{*}{ Case III } & Accounting Leads & $\begin{array}{l}\text { A financial reporting rule is followed for financial reporting purposes, and also for tax purposes. } \\
\text { This is possible because of the absence of a sufficiently specific (or singular) tax rule. }\end{array}$ \\
\hline & $\begin{array}{l}\text { Accounting Leads } \\
\text { (but with reverse effect) }\end{array}$ & $\begin{array}{l}\text { Financial reporting rules contain options or allow interpretations, some of which lead to lower } \\
\text { or to later profit than others do. This is a motivation for choosing these options so that they will } \\
\text { then also be used for tax purposes, in the absence of a specific or singular tax rule. }\end{array}$ \\
\hline Case IV & Tax Leads & $\begin{array}{l}\text { A tax rule or option is followed for tax purposes, and also for financial reporting purposes. This } \\
\text { is possible because of the absence of a sufficiently specific (or singular) financial reporting rule. }\end{array}$ \\
\hline Case V & Tax dominates & $\begin{array}{l}\text { A tax rule or option is followed for tax and financial reporting purposes instead of a conflicting } \\
\text { financial reporting principle. }\end{array}$ \\
\hline
\end{tabular}

Note. ${ }^{\text {a }}$ Such disconnection will be recognized when distinct, independent and detailed tax and financial reporting operational rules exist. Even if measurement outcomes are essentially the same, the particular arena may still be characterized as Case I; the independence and completeness of the sets of rules 'disconnects' tax and accounting in an operational sense.

Source: Adapted from Nobes and Schwencke (2006).

\section{Research Design and Sample Selection}

\subsection{The Research Method}

For each sample company, we compare the amount of bad debt expense accounted for to the maximum tax-deductible one. The first amount can be derived from income statement. It is the item 10.d. of the income statement prepared according to Italian law. Instead, the second amount cannot be derived from the income statement and cannot be reconstructed on the basis of the data obtainable from the income statement. Therefore, we use a proxy.

We define TBDE as the ratio between the amount of bad debt expense charged to the income statement (BDE) (item 10.d. of the income statement prepared according to Italian law) and the sum of the amount of trade receivables as it appears on the balance sheet (TR) (item C.II.1. of the balance sheet prepared according to Italian law) and the amount of bad debt expense charged to the income statement. In symbols, this is represented as:

$$
T B D E_{i t}=\frac{B D E_{i t}}{T R_{i t}+B D E_{i t}}
$$

where $i$ and $t$ are the company index and the year index, respectively.

We assume that TBDE corresponds to the maximum tax-deductible amount of bad debt expense when it falls in the interval of the frequency distribution of TBDE that includes the value 0.005 .

To test our research hypothesis, we adopt the distribution approach. It is based on the assumption that follows. If Italian companies were not likely to account for amounts of bad debt expense that correspond to the maximum tax-deductible amount, the frequency distribution of TBDE would be essentially smooth. Otherwise, such a frequency distribution would present a peak at the maximum tax-deductible amount and show discontinuities around it. Once the frequency distribution of TBDE has been constructed, a discontinuity emerges if the number of 
the actual observations that falls in a given interval is significantly higher than expected and if the number of the actual observations which falls in one or both of the immediately adjacent intervals is significantly lower than expected. The assumption is that the companies whose TBDEs would have had to fall in the under-represented interval have managed them in such a way as to ensure that they fall in the over-represented interval. Thus, the presence of a peak right at the maximum tax-deductible amount and discontinuities around that point appear to signal that Italian companies are likely to adopt tax rules.

To detect the peak and discontinuities, we use graphical and statistical analysis. The method we adopt is similar to that adopted by Burgstahler and Dichev (1997) to detect earnings management practices.

With reference to the graphical analysis, we construct and explore the graphical representation of the frequency distribution of TBDE. To do so, we use histograms in which the x-axis shows the intervals of TBDE and the y-axis shows frequencies, namely the percentages of the observations that fall in each interval of TBDE. The construction of the histograms requires the definition of TBDE and interval amplitudes. With reference to TBDE, we use equation (1). With reference to the interval amplitude, according to Silverman (1986), we defined it as follows:

$$
A=0.79 \times I Q \times N^{-\frac{1}{5}}
$$

Where: $\mathrm{A}$ is the interval amplitude; IQ is the interquartile range, namely the difference between the third and the first quartile of the distribution; $\mathrm{N}$ is the total number of observations.

Applying such a method, the interval amplitude is about 0.0009 . Our study shows the results referring to this interval amplitude. However, we repeated the investigation using different interval amplitudes (e.g. Scott, 1979; Silverman, 1986) obtaining results that are qualitatively similar to those that are shown.

With reference to the statistical analysis, to estimate the statistical significance of the discontinuities which may emerge in the frequency distributions of TBDE, we use the Garrod et al. (2006) test statistic $(\tau)$. Burgstahler and Dichev (1997) and Takeuchi (2004) have proposed and used other test statistics to verify the statistical significance of discontinuities in frequency distributions. We use the test statistic of Garrod et al. (2006) because it does not require the assumption of any particular distribution of the underlying data. Instead, the other test statistics assume the normal distribution of the underlying data. The Garrod et al. (2006) test statistic is defined as follows:

$$
\tau_{i}=\frac{\tilde{X}_{i}-E\left(X_{i}\right)}{\sqrt{\operatorname{var}\left(X_{i}\right)}}
$$

Where: $\tau_{\mathrm{i}}$ is the test statistic, referring to interval $\mathrm{i} ; \widetilde{\mathrm{X}}_{\mathrm{i}}$ is the actual number of observations which fall in interval $\mathrm{i}$; $X_{i}$ is the expected number of observations which fall in interval $i$.

According to Garrod et al. (2006, p. 10), "[a]ssuming that events are independent, the random variable $X_{i}$ is distributed binomially with parameters $\left(N, p_{i}\right)$, so that $E\left(X_{i}\right)=N \cdot p_{i}$ and $\operatorname{var}\left(X_{i}\right)=N \cdot p_{i} \cdot\left(1-p_{i}\right)$. The probability $\mathrm{p}_{\mathrm{i}}$ will depend on the nature of the null hypothesis. When testing for continuity of the distribution of $\widetilde{\mathrm{X}}_{\mathrm{i}}, \mathrm{p}_{\mathrm{i}}$ will be some kind of average of adjacent intervals". As in Garrod et al. (2006, p. 12), "[t]o test the continuity of the distribution we take for $p_{i}$ the arithmetic average of two adjacent intervals":

$$
p_{i}=\frac{\tilde{X}_{i-1}+\tilde{X}_{i+1}}{2 N}
$$

Where: $\widetilde{X}_{\mathrm{i}}$ is the actual number of observations that fall in interval $\mathrm{i} ; \mathrm{N}$ is the total number of observations.

We report the results relating to the above assumption. However, to test the robustness of the results, we repeated the investigation using different mean values obtaining results that are qualitatively similar to those we report.

According to Garrod et al. (2006, p. 10), "the values of the test statistic at traditional levels of significance are for the significance level of $10 \%|\tau|=3.1623$, for the significance level of $5 \%|\tau|=4.4721$ and for the significance level of $1 \%|\tau|=10 \%$.

\subsection{Sample Selection and Data}

The sample of Italian companies used to test our research hypothesis was extracted (on 5th May 2014) from the "Analisi Informatizzata Delle Aziende" (AIDA) database supplied by Bureau van Dijk. The AIDA database provides financial statement data for a vast set of Italian private and public companies operating in sectors other than the financial one. The companies included in the sample: are active; are obliged to prepare a financial statement; operate in sectors other than the financial one; are unlisted; prepare (non-consolidated) financial 
reporting according to the Italian national accounting standards; have the financial reporting available in the database for each year in the period 2004-2012; have a known value of trade receivables in each year in the period 2004-2010; have a number of employees higher than 50 in each year in the period 2004-2012.

The sample includes a total of 55755 firm-year observations (corresponding to 6195 companies for 9 consecutive years). Table 2 shows the main descriptive statistics referring to them.

Table 2. Main descriptive statistics referring to the sample

\begin{tabular}{|c|c|c|c|c|c|c|c|c|c|c|}
\hline & \multicolumn{9}{|c|}{ Years } & \multirow[b]{2}{*}{ Total } \\
\hline & 2012 & 2011 & 2010 & 2009 & 2008 & 2007 & 2006 & 2005 & 2004 & \\
\hline OBS & 6195 & 6195 & 6195 & 6195 & 6195 & 6195 & 6195 & 6195 & 6195 & 55755 \\
\hline \multicolumn{11}{|l|}{ REC } \\
\hline Q1 & 0.14 & 0.15 & 0.16 & 0.16 & 0.17 & 0.20 & 0.20 & 0.20 & 0.20 & 0.17 \\
\hline Q2 & 0.26 & 0.27 & 0.28 & 0.27 & 0.29 & 0.32 & 0.33 & 0.33 & 0.33 & 0.30 \\
\hline Q3 & 0.39 & 0.41 & 0.41 & 0.41 & 0.42 & 0.46 & 0.47 & 0.46 & 0.46 & 0.43 \\
\hline $\mathrm{AM}$ & 0.28 & 0.29 & 0.30 & 0.29 & 0.31 & 0.33 & 0.34 & 0.33 & 0.34 & 0.31 \\
\hline SD & 0.18 & 0.19 & 0.19 & 0.18 & 0.19 & 0.19 & 0.19 & 0.19 & 0.19 & 0.19 \\
\hline VI & 0.66 & 0.64 & 0.62 & 0.63 & 0.61 & 0.57 & 0.56 & 0.56 & 0.55 & 0.60 \\
\hline BDE & $78 \%$ & $78 \%$ & $78 \%$ & $77 \%$ & $77 \%$ & $75 \%$ & $74 \%$ & $75 \%$ & $75 \%$ & $76 \%$ \\
\hline Q1 & 0.0050 & 0.0050 & 0.0050 & 0.0050 & 0.0050 & 0.0049 & 0.0048 & 0.0049 & 0.0049 & 0.0049 \\
\hline Q2 & 0.0069 & 0.0056 & 0.0054 & 0.0056 & 0.0054 & 0.0052 & 0.0051 & 0.0052 & 0.0052 & 0.0053 \\
\hline Q3 & 0.0266 & 0.0181 & 0.0160 & 0.0179 & 0.0145 & 0.0097 & 0.0094 & 0.0105 & 0.0106 & 0.0142 \\
\hline $\mathrm{AM}$ & 0.0646 & 0.0475 & 0.0304 & 0.0296 & 0.0261 & 0.0270 & 0.0229 & 0.0258 & 0.0155 & 0.0323 \\
\hline SD & 0.2029 & 0.1734 & 0.1185 & 0.1122 & 0.1035 & 0.1225 & 0.1081 & 0.1147 & 0.0523 & 0.1309 \\
\hline VI & 3.1427 & 3.6508 & 3.8961 & 3.7921 & 3.9708 & 4.5411 & 4.7261 & 4.4476 & 3.3676 & 4.0475 \\
\hline
\end{tabular}

Note. Table 2 shows the main descriptive statistics referring to the sample. The symbols in the first column correspond as follows: OBS = observations; REC = incidence of trade receivables on total assets; $\mathrm{BDE}=$ percentage of companies that have accounted for bad debt expense; $\mathrm{Q} 1$ = first quartile; $\mathrm{Q} 2$ = second quartile (or median); Q3 = third quartile; $\mathrm{AM}=$ arithmetic mean; $\mathrm{SD}=$ standard deviation; VI = variation index (calculated as the ratio between the standard deviation and the absolute value of the arithmetic mean). The first set of descriptive statistics refers to REC, regarding the overall sample. The second set of descriptive statistics refers to TBDE, as defined in our paper, regarding the companies that have accounted for bad debt expense.

\section{Findings and Discussion}

Figure 1 shows the TBDE frequency distribution of the Italian companies included in the sample that have accounted for bad debt expense. The frequency distribution is truncated to the right. Only the first twenty intervals are shown.

The frequency distribution presents a trend that is convex both to the left and to the right of interval 6 (corresponding to the interval $0.0043 \neg 0.0052$ ), with a peak of observations in interval 6 and discontinuities both to the left and to the right of it. Interval 6 corresponds to the range of values we have assumed as corresponding to the maximum tax-deductible amount of bad debt expense. Because about $31 \%$ of the total observations fall into interval 6, we can say that this same amount of observations falls within the range of values we assume correspond to the maximum tax-deductible amount of bad debt expense. 


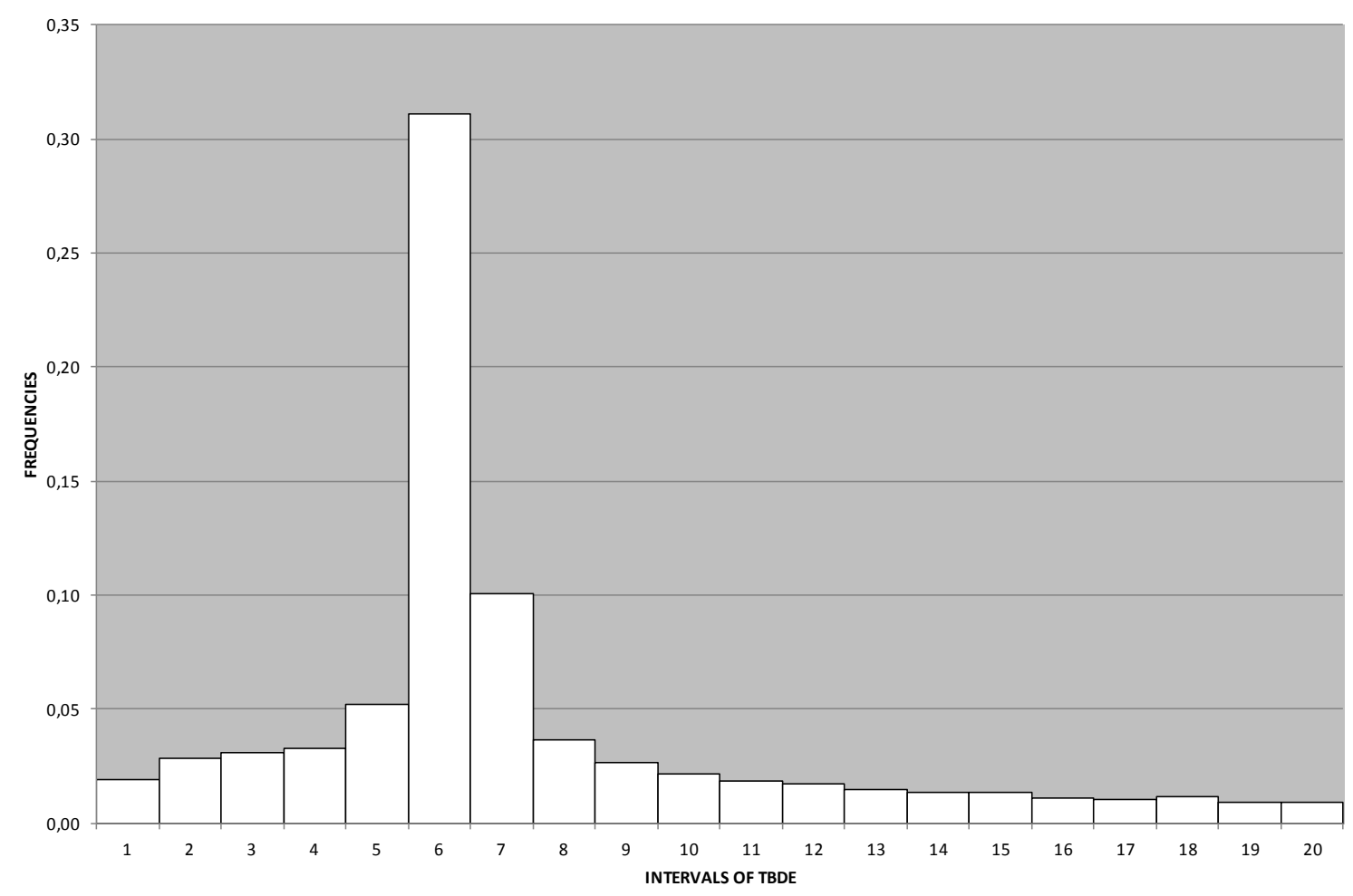

Figure 1. TBDE frequency distribution

Note. Figure 1 shows the frequency distribution of the TBDE of Italian companies included in the sample that have accounted for bad debt expense. The $\mathrm{x}$-axis shows the intervals of TBDE and the $\mathrm{y}$-axis shows frequencies, namely the percentages of the observations that fall in each interval of TBDE. Applying Silverman's (1986) method, the interval amplitude is about 0.0009 . The frequency distribution is truncated to the right. Only the first twenty intervals are shown.

Table 3 shows the values and the corresponding $p$-values of the test statistic $\tau$ referring to intervals 4 through 8 of the TBDE frequency distribution. It shows the test statistic $\tau$ only for the intervals for which the difference between the actual number of observations and the expected number of observations, determined on the basis of the assumptions we have made, is statistically significant. It allows us to observe the statistical significance of the discontinuities that emerged in the graphical analysis of the TBDE frequency distribution.

Table 3. Test statistic $\tau$ referring to intervals 4-8 of the TBDE frequency distribution

\begin{tabular}{ccccc}
\hline Interval & $\widetilde{X}_{l}$ & $E\left(X_{i}\right)$ & $\sqrt{\operatorname{var}\left(X_{i}\right)}$ & $\left|\tau_{i}\right|$ \\
\hline 4 & 1395 & 1757 & 0.0412 & $-8.8090^{* *}$ \\
5 & 2210 & 7322 & 0.1719 & $-65.6486^{* * *}$ \\
6 & 13249 & 3244 & 0.0761 & $182.7794^{* * *}$ \\
7 & 4277 & 7403 & 0.1738 & $-39.9700^{* * *}$ \\
8 & 1557 & 2701 & 0.0634 & $-22.7450^{* * *}$
\end{tabular}

Note. Table 3 shows the test statistic $\tau$ only for the intervals for which the difference between the actual number of observations and the expected number of observations, determined on the basis of the assumptions we have made, is statistically significant. ** corresponds to a level of significance of $5 \%$. *** correspond to a level of significance of $1 \%$.

Table 3 confirms the presence of the discontinuities that emerged in the graphical analysis of the TBDE frequency distribution. There are statistically significant differences between actual and expected observations in intervals 4-8. Interval 6 is over-represented, while the other intervals are under-represented. 
We believe that the under-representation of intervals 4 and 5 may be due to the fact that companies are likely to increase the amount of bad debt expense reporting up to the maximum tax-deductible level. Similarly, we believe that the under-representation of intervals 7 and 8 may be due to the fact that companies are likely to decrease the amount of bad debt expense reported so as to remain within the maximum tax-deductible level. Thus, our research hypothesis is confirmed. As a result, the Italian companies included in the sample are likely to account for the maximum tax-deductible amount of bad debt expense.

\section{Conclusion}

Our study has shown that Italian companies are likely to adopt the tax rules, rather than the accounting ones, to measure receivables for the preparation of financial statements. On the one hand, companies that should account for bad debt expense for amounts that are inferior to the maximum tax-deductible allowance are likely to increase their bad debt expense accounted for to the maximum tax-deductible amount. On the other hand, companies that should account for bad debt expense for amounts that are greater than the maximum tax-deductible allowance, are likely to decrease their bad debt expense accounted for so that it meets the maximum tax-deductible amount. As a result, the measurement of receivables for the preparation of financial statements appears to be affected by tax rules. This phenomenon appears to be quite widespread.

Our study has given empirical evidence to an assumption that does not appear to be sufficiently demonstrated in previous studies. Of these, Nobes and Schwencke (2006) have argued that a tax rule or option can be followed for tax purposes and also for financial reporting purposes when a sufficiently specific (or singular) financial reporting rule does not exist. To the best of our knowledge, there are no previous studies that have given empirical evidence of this assumption with reference to the Italian contest. Our study, albeit only for the measurement of receivables, has given empirical evidence to the fact that this phenomenon actually exists (and is quite common) among Italian private companies. This is the first and main contribution that our study gives to the literature on the relationship between accounting and tax rules for the preparation of financial statements.

Considering that the impact of tax rules on the preparation of the financial statements may affect the quality of earnings (Decow et al., 2010), the main implication of the findings of our study is that the earnings of Italian companies are not unconditionally informative regarding the company's performance. In other words, they may be of poor quality, confirming the findings of previous studies (e.g., Poli, 2012, 2013a, 2013b, 2013c). As a result, they should be interpreted with caution by those who use financial statement information. This is the second contribution that our study gives to the literature.

The main limitation of our study relates to the way we chose to consider TBDE as the maximum tax-deductible amount. The lack of data necessary to determine the exact value of the maximum tax-deductible amount of bad debt expense led us to adopt a proxy. In addition, it is difficult to distinguish the companies that account for the maximum tax-deductible amount of bad debt expense because it is genuinely representative of their credit risk from those that account for said amount only in order to obtain the greatest tax benefit, giving up a proper evaluation according to the rules of accounting. Such limitations suggest that caution should be used in interpreting the findings of our study.

Our study highlights a particular kind of impact that tax rules can have on the measurement of receivables for the preparation of financial statements. Within the sample, about $24 \%$ of the companies does not account for any bad debt expense and about 53\% accounts for bad debt expense above the maximum tax-deductible amount. Further studies could investigate whether and how such behaviors might also be affected by tax rules.

\section{References}

Aisbitt, S. (2002). Tax and accounting rules: Some recent development. European Business Review, 14(2), 92-97. http://dx.doi.org/10.1108/09555340210420064

Burgstahler, D. C., \& Dichev, I. (1997). Earnings management to avoid earnings decreases and losses. Journal of Accounting and Economics, 24(1), 99-126. http://dx.doi.org/10.1016/S0165-4101(97)00017-7

Dechow, P. M., Ge, W., \& Schrand, C. (2010). Understanding earnings quality: A review of the proxies, their determinants and their consequences. Journal of Accounting and Economics, 50(2-3), 344-401. http://dx.doi.org/10.1016/j.jacceco.2010.09.001

Garrod, N., Pirkovic, S. R., \& Valentincic, A. (2006). Testing for discontinuity or type of distribution. Mathematics and Computers in Simulation, 71(1), 9-15. http://dx.doi.org/10.1016/j.matcom.2005.09.002

Gavana, G., Guggiola, G., \& Marenzi, A. (2013). Evolving connections between tax and financial reporting in Italy. Accounting in Europe, 10(1), 43-70. http://dx.doi.org/10.1080/17449480.2013.774733 
Gee, M., Haller, A., \& Nobes, C. (2010). The influence of tax on IFRS consolidated statements: The convergence of Germany and the UK. Accounting in Europe, 7(1), 97-122. http://dx.doi.org/10.1080/17449480.2010.485382

Hogendoorn, M. N. (1996). Accounting and taxation in Europe: A comparative overview. European Accounting Review, 5(Supplement), 783-794. http://dx.doi.org/10.1080/09638189600000050

Istrate, C. (2011). Evolution in the accounting-taxation (dis)connection in Romania, after 1990. Review of Economic \& Business Studies, 4(2), 43-61.

Lamb, M., Nobes, C., \& Roberts, A. (1998). International variations in the connections between tax and financial $\begin{array}{llll}\text { reporting. Accounting and } & \text { Business }\end{array}$ http://dx.doi.org/10.1080/00014788.1998.9728908

Marasca, S. (1999). Le valutazioni nel bilancio di esercizio. Torino, Italia: G. Giappichelli Editore.

Nobes, C. (1998). Towards a general model of the reasons for international differences in financial reporting. Abacus, 34(2), 162-186. http://dx.doi.org/10.1111/1467-6281.00028

Nobes, C. (2008). Accounting classification in the IFRS Era. Australian Accounting Review, 18(3), 191-197. http://dx.doi.org/10.1111/j.1835-2561.2008.0024.x

Nobes, C., \& Schwencke, H. R. (2006). Modelling the links between tax and financial reporting: A longitudinal examination of Norway over 30 years up to IFRS adoption. European Accounting Review, 15(1), 63-87. http://dx.doi.org/10.1080/09638180500510418

Oliveras, E., \& Puig, X. (2007). The changing relationship between tax and financial reporting in Spain. Accounting in Europe, 2(1), 195-207. http://dx.doi.org/10.1080/09638180500379020

Poli, S. (2012). La svalutazione delle immobilizzazioni materiali nei bilanci delle imprese italiane. Torino, Italia: G. Giappichelli Editore.

Poli, S. (2013a). Small-sized companies' earnings management: Evidence from Italy. International Journal of Accounting and Financial Reporting, 3(2), 93-109. http://dx.doi.org/10.5296/ijafr.v3i2.4191

Poli, S. (2013b). The application of the accounting concept of materiality in the Italian listed companies' financial statement. International Journal of Finance and Accounting, 2(4), 214-219. http://dx.doi.org/10.5923/j.ijfa.20130204.04

Poli, S. (2013c). The Italian unlisted companies' earnings management practices: The impacts of fiscal and financial incentives. Research Journal of Finance and Accounting, 4(11), 48-60.

Quagli, A. (2013). Bilancio di esercizio e principi contabili (6th ed.). Torino, Italia: G. Giappichelli Editore.

Scott, D. W. (1992). Multivariate density estimation: Theory, practice, and visualization. New York, NY: Wiley. http://dx.doi.org/10.1002/9780470316849

Silverman, B. W. (1986). Density estimation for statistics and data analysis. London, UK: Chapman \& Hall. http://dx.doi.org/10.1007/978-1-4899-3324-9

Takeuchi, Y. (2004). On a statistical method to detect discontinuity in the distribution function of reported earnings. Mathematics and Computers in Simulation, 64(1), 103-111. http://dx.doi.org/10.1016/S0378-4754(03)00124-1

\section{Copyrights}

Copyright for this article is retained by the author(s), with first publication rights granted to the journal.

This is an open-access article distributed under the terms and conditions of the Creative Commons Attribution license (http://creativecommons.org/licenses/by/3.0/). 